\title{
The Lymph Node Ratio Is an Independent Prognostic Factor in Esophageal Cancer Patients Who Receive Curative Surgery
}

\author{
NORIO YUKAWA $^{1 *}$, TORU AOYAMA ${ }^{1 *}$, HIROSHI TAMAGAWA ${ }^{1}$, AYAKO TAMAGAWA $^{1}$, \\ YOSUKE ATSUMI ${ }^{1}$, SHINNOSUKE KAWAHARA ${ }^{1}$, YUKIO MAEZAWA ${ }^{1,2}$, KAZUKI KANO $^{1}$, \\ MASAAKI MURAKAWA ${ }^{1}$, KEISUKE KAZAMA ${ }^{1}$, MASAKATSU NUMATA ${ }^{1}$, \\ TAKASHI OSHIMA ${ }^{1,3}$, MUNETAKA MASUDA $^{1}$ and YASUSHI RINO ${ }^{1}$ \\ ${ }^{1}$ Department of Surgery, Yokohama City University, Yokohama, Japan; \\ ${ }^{2}$ Department of Surgery, Tokyo Metropolitan Cancer and \\ Infectious Disease Center Komagome Hospital, Tokyo, Japan; \\ ${ }^{3}$ Department of Gastrointestinal Surgery, Kanagawa Cancer Center, Yokohama, Japan
}

\begin{abstract}
Background/Aim: We investigated the clinical impact of the lymph node ratio (LNR) on overall survival $(O S)$ and recurrence-free survival (RFS) in esophageal cancer patients who underwent curative surgery. Patients and Methods: One hundred twenty patients who underwent curative surgery for esophageal cancer between 2005 and 2017 were included in this study. The LNR was defined as the ratio of the number of metastatic lymph nodes (LNs) to the total number of harvested LNs. Results: A lymph node ratio of $10 \%$ was regarded as the optimal critical point for classification based on the overall survival rate. The 3-year and 5-year OS rates were $65.5 \%$ and $57.0 \%$, respectively, in the $L N R<10 \%$ group, and $11.8 \%$ and $0 \%$ in the $L N R \geq 10 \%$ group; the difference was statistically significant $(p<0.001)$. The 3-year and 5-year RFS rates were $52.6 \%$ and $44.6 \%$, respectively, in the $L N R<10 \%$ group, and $0 \%$ and $0 \%$ in the $L N R>10 \%$ group; the difference was also statistically significant $(p<0.001)$. When comparing the sites of first relapse, the incidence of distant lymph node metastasis in the $L N R>10 \%$ group was significantly higher than that in the $L N R<10 \%$ group. Conclusion: The LNR was a risk factor for both $O S$ and RFS in patients who underwent curative surgery for esophageal cancer.
\end{abstract}

This article is freely accessible online.

*These Authors contributed equally to this study.

Correspondence to: Toru Aoyama, Department of Gastrointestinal Surgery, Kanagawa Cancer Center, 2-3-2 Nakao, Asahi-ku, Yokohama 241-8515, Japan. E-mail: t-aoyama@lilac.plala.or.jp

Key Words: Esophageal cancer, lymph node ratio, survival, recurrence.
Esophageal cancer is the seventh-most common cancer and the sixth leading cause of cancer-related mortality (1). Esophagectomy with lymphadenectomy and perioperative adjuvant treatment are essential to cure resectable esophageal cancer (2-4). However, more than half of the esophageal cancer patients suffer recurrence, even after curative treatment. Thus, the identification of prognostic factors is necessary to improve the survival of esophageal cancer patients.

Common sites of recurrence in patients with esophageal cancer include the lymph nodes, lung, liver, and local sites (5, 6). Among these, lymph node recurrence is one of the most frequent sites of recurrence, because tumor cells spread radially via the lymphatic system. Thus, the evaluation of both the number of harvested lymph nodes (LNs) and the number of metastasis-positive lymph nodes are important in esophageal cancer treatment. Previously, the TNM staging system simply provided LN classification according to the absence or presence of LN metastasis. In 2010, the TNM staging system, $7^{\text {th }}$ edition, was published by the American Joint Committee on Cancer (AJCC). According to this revised TNM staging system, the $\mathrm{N}$ category was stratified by the number of the positive lymph nodes $(7,8)$. However, TNM staging system did not define the optimal number of harvested lymph nodes for accurate nodal staging. To improve the survival of esophageal cancer patients, it is necessary to more effectively utilize the lymph node metastasis status.

Recently, the lymph node ratio (LNR), which was defined as the ratio of the number of metastatic LNs relative to the total number of harvested LNs, has been proposed to be a sensitive indicator of survival in various types of gastrointestinal cancer (9-12). However, it is unclear whether the LNR has clinical impact in esophageal cancer patients who receive curative treatment. In addition, the optimal cutoff points of the LNR are still controversial (13-15). In the present study, we investigated the clinical impact of the LNR on 
Table I. Comparison of survival rates stratified by patient characteristics.

\begin{tabular}{|c|c|c|c|c|c|}
\hline Characteristics & No. of patients (\%) & $\begin{array}{l}\text { 1-year survival } \\
\text { rate }(\%)\end{array}$ & $\begin{array}{c}\text { 3-year survival } \\
\text { rate }(\%)\end{array}$ & $\begin{array}{c}5 \text {-year survival } \\
\text { rate }(\%)\end{array}$ & $p$-Value \\
\hline Age (years) & & & & & 0.067 \\
\hline$<68$ & $56(46.7)$ & 75.7 & 47.7 & 36.3 & \\
\hline$\geq 68$ & $64(53.3)$ & 85.4 & 64.6 & 57.9 & \\
\hline Gender & & & & & 0.153 \\
\hline Male & $104(86.7)$ & 80.1 & 53.8 & 45.9 & \\
\hline Female & $16(13.3)$ & 86.7 & 79.4 & 66.2 & \\
\hline Site of tumor & & & & & 0.530 \\
\hline Upper & $35(29.2)$ & 80.3 & 54.8 & 44.2 & \\
\hline Middle or Lower & $85(71.8)$ & 82.4 & 62.8 & 47.1 & \\
\hline Metastatic lymph node ratio & & & & & $<0.001$ \\
\hline $0 \%$ & $61(50.8)$ & 84.8 & 68.2 & 61.7 & \\
\hline $0 \%$ to $<5 \%$ & $27(22.5)$ & 88.6 & 60.2 & 49.3 & \\
\hline $5 \%$ to $<10 \%$ & $14(11.7)$ & 76.9 & 61.5 & 52.8 & \\
\hline$\geq 10 \%$ & $18(15.0)$ & 58.8 & 11.8 & 0.0 & \\
\hline UICC T status & & & & & 0.007 \\
\hline $\mathrm{T} 1$ & 44 (36.7) & 93.1 & 73.3 & 69.8 & \\
\hline $\mathrm{T} 2$ to $\mathrm{T} 3$ & $76(63.3)$ & 73.7 & 47.6 & 36.9 & \\
\hline Lymph vascular invasion & & & & & 0.025 \\
\hline Negative & $38(31.7)$ & 89.0 & 74.6 & 68.4 & \\
\hline Positive & $82(68.3)$ & 77.1 & 49.1 & 40.4 & \\
\hline Lymph node dissection & & & & & 0.651 \\
\hline Two-field & 74 (61.7) & 80.4 & 57.8 & 44.3 & \\
\hline Three-field & $46(38.3)$ & 81.7 & 56.4 & 56.4 & \\
\hline Neoadjuvant therapy & & & & & 0.652 \\
\hline Yes & $51(42.5)$ & 87.3 & 58.8 & 51.5 & \\
\hline No & $69(57.5)$ & 76.8 & 55.6 & 46.4 & \\
\hline
\end{tabular}

UICC: Union for International Cancer Control.

overall survival (OS) and recurrence-free survival (RFS) in esophageal cancer patients who received curative treatment.

\section{Patients and Methods}

Patients. The medical records of consecutive patients who were diagnosed with primary esophageal adenocarcinoma or squamous cell carcinoma and who underwent complete resection at Yokohama City University from January 2005 to December 2017 were included on this study.

Surgical procedure. Our standard procedure consisted of open subtotal esophagectomy via right thoracotomy. A greater curvature tube was used for reconstruction. The patients who had a tumor in the middle to lower thoracic esophagus received two-field lymph node dissection, while the patients who had a tumor in the upper thoracic esophagus received three-field lymph node dissection.

Lymph node harvesting methods and pathological diagnosis. The LNs were harvested from the specimen immediately after surgery. First, the surgeons removed the palpable LNs. Second, the surgeons stretched the fat tissues, which included the LNs to detect visible LNs. Then, the harvested LNs were fixed with $10 \%$ buffered formalin for 48 hours. After standard histological processing, twostep sections were cut from each block and stained with eosin and hematoxylin $(\mathrm{H} \& \mathrm{E})$. Experienced pathologists examined all slides.

Evaluations and statistical analyses. The lymph node ratio (LNR) was defined as the ratio of the number of metastatic lymph nodes to the total number of lymph nodes examined. Fisher's exact test or the $\chi^{2}$ test were used to assess associations between LNR and each parameter. The Kaplan-Meier method and log-rank test were used to calculate and compare overall survival (OS) and recurrence-free survival (RFS). The univariate and multivariate survival analyses were performed using a Cox proportional hazards model. $p$-Values of $<0.05$ were considered to indicate statistical significance. The SPSS software program (v11.0 J Win, SPSS, Chicago, IL, USA) was used for all of the statistical analyses. This study was approved by the Institutional Review Board of the Yokohama City University.

\section{Results}

Patients. One hundred twenty patients (male, $\mathrm{n}=104$; female, $\mathrm{n}=16$ ) were evaluated in the present study. The median age was 68 years (range $=40-82$ years). The median follow-up period was 72.5 months (range $=13.9-125.2$ months). The median operation time was 570 minutes (range $=236-911$ min). The median blood loss was $541 \mathrm{ml}$ (range $=70-3000$ $\mathrm{ml}$ ). Seventy-four patients received two-field lymph node dissection and 36 patients received three-field lymph node 
Yukawa et al: Lymph Node Ratio and Survival of Esophageal Cancer

Table II. Uni and multivariate Cox proportional hazards analysis of clinico-pathological factors for overall survival.

\begin{tabular}{|c|c|c|c|c|c|c|c|}
\hline \multirow[t]{2}{*}{ Factors } & \multirow[t]{2}{*}{ No } & \multicolumn{3}{|c|}{ Univariate analysis } & \multicolumn{3}{|c|}{ Multivariate analysis } \\
\hline & & OR & $95 \% \mathrm{CI}$ & $p$-Value & OR & $95 \% \mathrm{CI}$ & $p$-Value \\
\hline Age (years) & & & & 0.044 & & & 0.023 \\
\hline$<68$ & 56 & 1.000 & & & 1.000 & & \\
\hline$\geq 68$ & 64 & 1.772 & $1.016-3.094$ & & 1.874 & $1.091-3.219$ & \\
\hline Gender & & & & 0.220 & & & \\
\hline Female & 16 & 1.000 & & & & & \\
\hline Male & 104 & 1.932 & $0.675-5.531$ & & & & \\
\hline Metastatic lymph node ratio & & & & $<0.001$ & & & $<0.001$ \\
\hline$<10 \%$ & 102 & 1.000 & & & 1.000 & & \\
\hline$\geq 10 \%$ & 18 & 3.766 & $1.934-7.335$ & & 4.301 & $2.293-8.068$ & \\
\hline Site of tumor & & & & 0.811 & & & \\
\hline Middle or Lower & 85 & 1.000 & & & & & \\
\hline Upper & 35 & 1.083 & $0.561-2.092$ & & & & \\
\hline UICC T status & & & & 0.394 & & & \\
\hline $\mathrm{T} 1$ & 44 & 1.000 & & & & & \\
\hline $\mathrm{T} 2$ or $\mathrm{T} 3$ & 76 & 1.383 & $0.656-2.917$ & & & & \\
\hline Lymphovascular invasion & & & & 0.213 & & & 0.077 \\
\hline Negative & 38 & 1.000 & & & 1.000 & & \\
\hline Positive & 82 & 1.610 & $0.761-3.405$ & & 1.841 & $0.935-3.626$ & \\
\hline Lymph node dissection & & & & 0.811 & & & \\
\hline Two-field & 74 & 1.000 & & & & & \\
\hline Three-field & 46 & 1.083 & $0.561-2.092$ & & & & \\
\hline Neoadjuvant therapy & & & & 0.568 & & & \\
\hline Yes & 51 & 1.000 & & & & & \\
\hline No & 69 & 1.189 & $0.657-2.151$ & & & & \\
\hline
\end{tabular}

UICC: Union for International Cancer Control.

dissection. The median number of harvested lymph nodes was 37 (range $=7-118)$.

Survival analysis. OS was stratified by each clinical factor, compared by the log-rank test (Table I). There were significant differences in the lymph node ratio, lymphovascular invasion, and UICC T factor. An LNR of $10 \%$ was regarded as the optimal cutoff value for classification according to the OS rate.

The univariate and multivariate analysis of factors associated with OS in shown in Table II. LNR was identified as a significant prognostic factor in both the univariate and multivariate analyses. The 3-year and 5-year OS rates were $65.5 \%$ and $57.0 \%$, respectively, in the LNR $<10 \%$ group, and $11.8 \%$ and $0 \%$ in the $\mathrm{LNR} \geq 10 \%$ group $(p<0.001)$. Figure 1 shows the OS curves of the LNR $<10 \%$ and LNR $>10 \%$ groups.

Table III shows the univariate and multivariate analysis of factors associated with RFS. The LNR was identified as a significant prognostic factor in both the univariate and multivariate analyses. The 3-year and 5-year RFS rates were $52.6 \%$ and $44.6 \%$, respectively, in the LNR $<10 \%$ group, and $0 \%$ and $0 \%$ in the LNR $>10 \%$ group $(p<0.001)$. The RFS curves in the $\mathrm{LNR}<10 \%$ and the $\mathrm{LNR}>10 \%$ groups are shown in Figure 2.
Table IV shows the sites of first relapse in the LNR $<10 \%$ and LNR $>10 \%$ groups. When the sites of first relapse were compared, the incidence of distant lymph node metastasis was significantly higher in the $\mathrm{LNR} \geq 10 \%$ group than in the LNR $<10 \%$ group.

\section{Discussion}

The aim of the present study was to evaluate the clinical impact of the LNR, which was defined as the ratio of the number of metastatic LNs relative to the total number of harvested LNs, in patients who underwent curative resection for esophageal cancer. The major finding of the present study was that the LNR was a significant prognostic factor in patients who underwent curative resection for esophageal cancer. Thus, the LNR might be a useful tool for assessing the lymph node metastasis status in esophageal cancer.

The present study demonstrated that the LNR was a significant risk factor for esophageal cancer patients after esophagectomy. Limited studies have shown the similar results. Mariette et al. have evaluated the prognostic impact of the ratio of metastatic lymph nodes to harvested lymph nodes in 536 esophageal cancer patients who received curative en bloc esophagectomy (16). They set the cutoff 


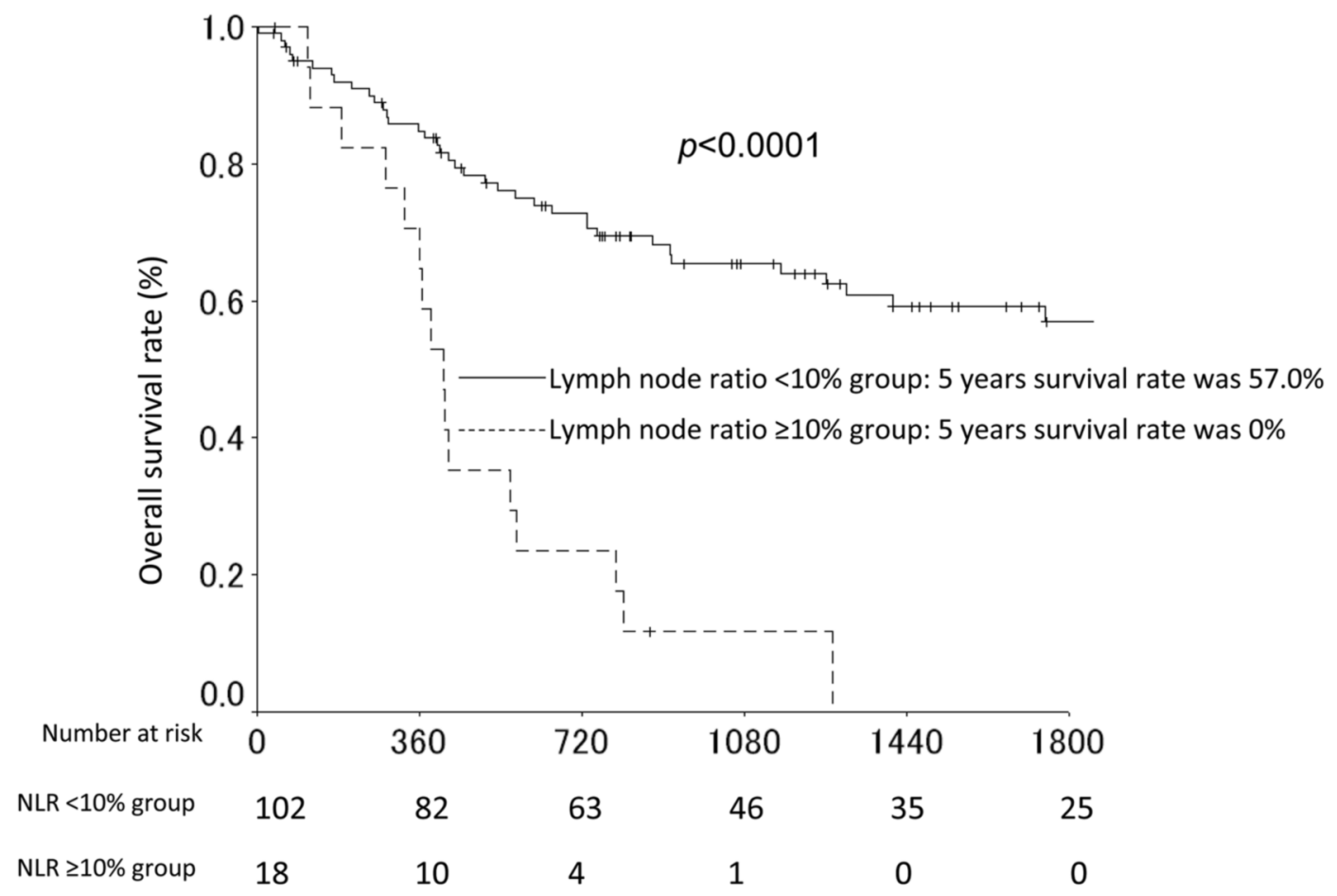

Figure 1. A comparison of the overall survival between the LNR $<10 \%$ group and the LNR $>10 \%$ group.

Table III. Uni and multivariate Cox proportional hazards analysis of clinicopathological factors for recurrence-free survival.

\begin{tabular}{|c|c|c|c|c|c|c|c|}
\hline \multirow[t]{2}{*}{ Factors } & \multirow[t]{2}{*}{ No } & \multicolumn{3}{|c|}{ Univariate analysis } & \multicolumn{3}{|c|}{ Multivariate analysis } \\
\hline & & OR & $95 \% \mathrm{CI}$ & $p$-Value & OR & $95 \% \mathrm{CI}$ & $p$-Value \\
\hline Age (years) & & & & 0.178 & & & \\
\hline$<68$ & 56 & 1.000 & & & & & \\
\hline$\geq 68$ & 64 & 1.434 & $0.849-2.422$ & & & & \\
\hline Gender & & & & 0.171 & & & \\
\hline Female & 16 & 1.000 & & & & & \\
\hline Male & 104 & 1.856 & $0.765-4.503$ & & & & \\
\hline Metastatic lymph node ratio & & & & $<0.001$ & & & $<0.001$ \\
\hline$<10 \%$ & 102 & 1.000 & & & 1.000 & & \\
\hline$\geq 10 \%$ & 18 & 3.096 & $1.671-5.738$ & & 3.085 & $1.679-5.669$ & \\
\hline Site of tumor & & & & 0.993 & & & \\
\hline Upper & 85 & 1.000 & & & & & \\
\hline Middle or Lower & 35 & 1.003 & $0.543-1.852$ & & & & \\
\hline UICC T status & & & & 0.035 & & & 0.002 \\
\hline $\mathrm{T} 1$ & 44 & 1.000 & & & 1.000 & & \\
\hline $\mathrm{T} 2$ or $\mathrm{T} 3$ & 76 & 2.134 & $1.056-4.314$ & & 2.699 & $1.423-5.123$ & \\
\hline Lymph vascular invasion & & & & 0.104 & & & \\
\hline Negative & 38 & 1.000 & & & & & \\
\hline Positive & 82 & 1.761 & $0.890-3.487$ & & & & \\
\hline Lymph node dissection & & & & 0.983 & & & \\
\hline Two-field & 74 & 1.000 & & & & & \\
\hline Three-field & 46 & 1.006 & $0.573-1.765$ & & & & \\
\hline Neoadjuvant therapy & & & & 0.474 & & & \\
\hline Yes & 51 & 1.000 & & & & & \\
\hline No & 69 & 1.223 & $0.704-2.123$ & & & & \\
\hline
\end{tabular}

UICC: Union for International Cancer Control. 


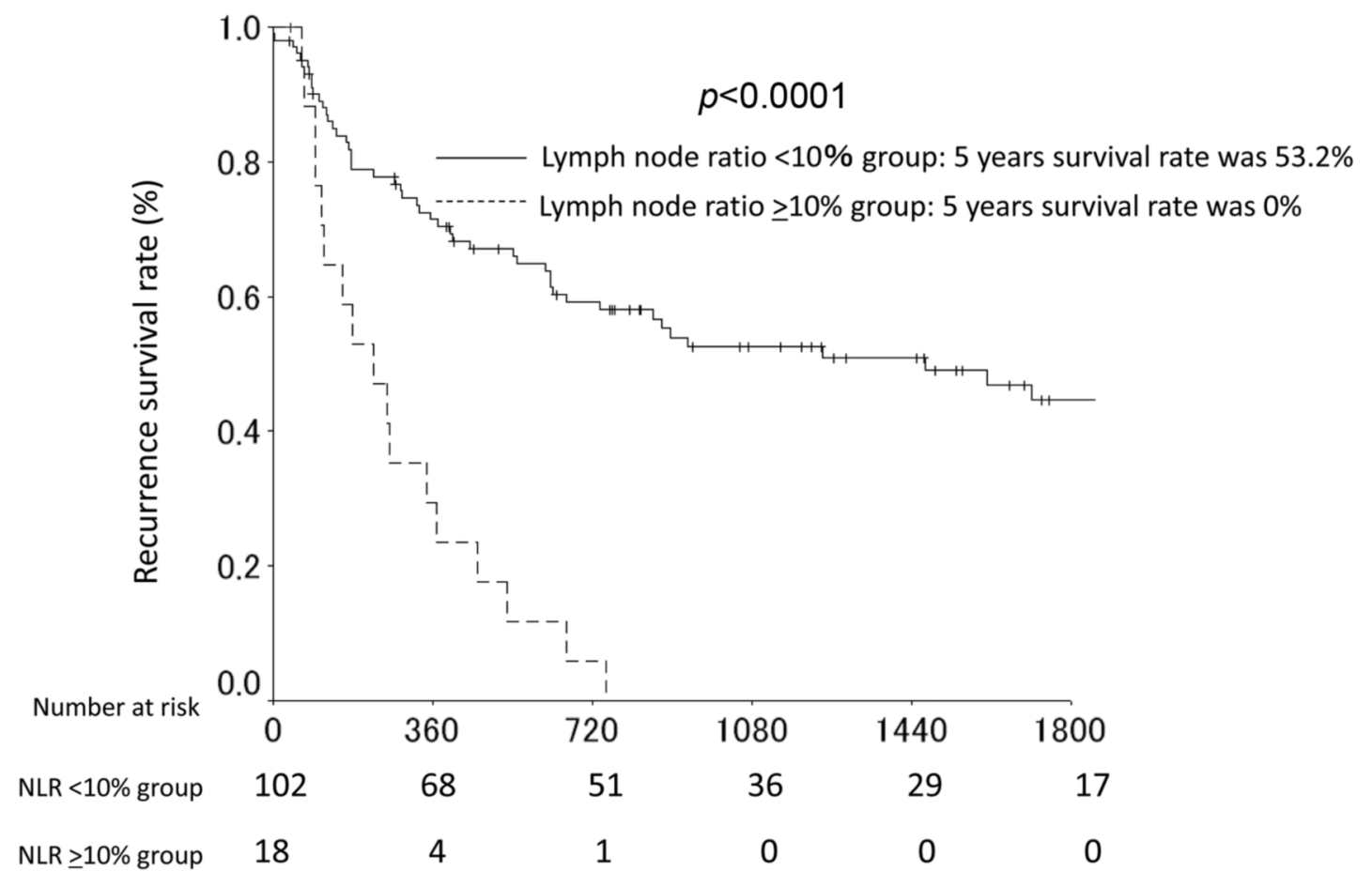

Figure 2. A comparison of the recurrence-free survival between the LNR $<10 \%$ group and the LNR $>10 \%$ group.

Table IV. Patterns of recurrence between the patients with metastatic lymph node ratio $<10 \%$ and those with metastatic lymph node ratio $\geq 10 \%$.

\begin{tabular}{|c|c|c|c|c|c|c|c|}
\hline \multirow[b]{3}{*}{ Recurrence site } & & & \multicolumn{4}{|c|}{ Metastatic lymph node ratio } & \multirow[b]{3}{*}{$p$-Value } \\
\hline & \multicolumn{2}{|c|}{ All cases } & \multicolumn{2}{|c|}{$<10 \%(\mathrm{n}=102)$} & \multicolumn{2}{|c|}{$\geq 10 \%(\mathrm{n}=18)$} & \\
\hline & Number & $\%$ & Number & $\%$ & Number & $\%$ & \\
\hline \multicolumn{8}{|l|}{ Lymph node } \\
\hline Regional & 22 & 18.3 & 16 & 15.7 & 6 & 33.3 & 0.074 \\
\hline Distant & 7 & 5.8 & 4 & 3.9 & 3 & 16.7 & 0.033 \\
\hline Local site & 11 & 9.2 & 10 & 9.8 & 1 & 5.6 & 0.565 \\
\hline \multicolumn{8}{|l|}{ Distant site } \\
\hline Lung & 13 & 10.8 & 10 & 9.8 & 3 & 16.7 & 0.388 \\
\hline Liver & 12 & 10.0 & 6 & 5.9 & 6 & 33.3 & 0.001 \\
\hline Bone & 5 & 4.2 & 5 & 4.9 & 0 & 0.0 & 0.337 \\
\hline Others & 9 & 7.5 & 7 & 6.9 & 2 & 11.1 & 0.528 \\
\hline
\end{tabular}

value of the ratio of metastatic lymph nodes to harvested lymph nodes (LNM) as 0.2 . When comparing the 5-year survival rates between the $\mathrm{LNM} \geq 0.2$ and $\mathrm{LNM}<0.2$ groups, there was a significant difference $(p<0.001)$. The 5-year survival rate was $22 \%$ in the $\mathrm{LNM} \geq 0.2$ group, and $53 \%$ in the $\mathrm{LNM}<0.2$ group. Univariate and multivariate analyses demonstrated that $\mathrm{LNM} \geq 0.2$ was a prognostic factor (Odds ratio $=1.9,95 \%$ conflict interval=1.2-3.0). In addition, Chen et al. have evaluated a modified staging system utilizing the lymph node ratio (LNR) in 2011 patients with esophageal squamous cell cancer (17). They defined the LNR as the ratio of metastatic lymph nodes to the total number of harvested lymph nodes and set the cut-off value of the LNR as $10 \%$. Patients were classified into four LNR categories: $\mathrm{Nr} 0$ (LNR=0), Nr1 (LNR; 0-10\%), Nr2 (LNR; 10-20\%), and $\mathrm{Nr} 3$ (LNR; > 20\%). They found that the median OS and 5year survival rate was 155 months and $61.1 \%$, in $\mathrm{Nr} 0,39$ months and $41.1 \%$ in $\mathrm{Nr} 1,28$ months and $33.0 \%$ in $\mathrm{Nr} 2$, and 
19 months and $22.9 \%$ in $\mathrm{Nr} 3$, respectively. There were statistically significant differences according to the LNR categories $(p=0.001)$. Considering the results of the present and the previous studies, the LNR might have a clinical impact in esophageal cancer patients after surgery.

In the present study, we set the cut-off value of the LNR as $10 \%$ according to the overall survival rate. There were some differences in the cut-off value in the present study and previous studies. For example, a further important limitation of all of the available data regarding LNR, including the current study, is the lack of consensus regarding the most appropriate cut-off point for the evaluation of the LNR. Previous studies have reported LNR cut offs ranging from 0.1 to 0.3 (18-20). For example, Mariette et al. set the cut-off value as 0.2 in 536 patients who received esophagectomy and Bhamidipati et al. used the same cut-off value $(0.2)$ in 347 consecutive patients who received esophagectomy for esophageal cancer $(16,18)$. In our study, we used a cut-off value of 0.1 according to 3 -year and 5-year survival rates. There are some differences between the previous studies and the present study. First, the sample size was different. Second, the perioperative adjuvant treatment was different. The previous reports only analyzed the patients who were treated with surgery alone, while the present study analyzed only patients who were treated with surgery and perioperative adjuvant treatment. The outcomes of patients with esophageal cancer have gradually improved with effective adjuvant treatment. Theoretically, effective adjuvant treatment could improve patient survival by inhibiting micro metastasis. Actually, a previous study has demonstrated that perioperative adjuvant treatment was associated with a reduced lymph node ratio in other gastrointestinal cancer $(21,22)$. Third, the median numbers of harvested lymph nodes differed between the previous studies and the present study. The LNR was affected by both the number of harvested lymph nodes and the number of metastatic lymph nodes. In the present study, the median number of harvested lymph nodes was 37 and the cut-off value of the LNR was $10 \%$. In contrast, Mariette et al. have reported mean number of harvested lymph nodes 19.6 and set the cut-off value of LNR at $20 \%$ (16). Moreover, Bhamidipati et al. have reported median number of harvested lymph nodes 13-15 and set the cut-off value of the LNR at $20 \%$ (17). The median number of metastatic lymph nodes in the present study was similar to that in previous studies. These differences might have affected the cut-off value of the LNR.

Special attention is required when interpreting the current results because the present study has several potential limitations. First, the present study was a retrospective analysis that was performed in a single institution. We cannot deny the possibility that our findings were observed by chance. Second, there was a selection bias in the patients in this series. Surgeons often avoid performing esophagectomy in some patients because the procedure is associated with high rates of morbidity and mortality (40-60\% and 1-5 respectively). Third, there was a time bias in the present study. The surgical procedure, perioperative care, and adjuvant treatment changed during the study period. Considering these limitations, the results must be confirmed in another cohort or in a prospective multicenter-study.

In conclusion, the OS and RFS of the esophageal cancer patients who underwent curative surgery differed significantly based on the LNR. It is necessary to develop strategies that effectively utilize the lymph node metastasis status.

\section{Conflicts of Interest}

The Authors declare that they have no conflicts of interest in association with the present study.

\section{Authors' Contributions}

Norio Yukawa and Toru Aoyama made substantial contributions to conception and design. Norio Yukawa, Toru Aoyama, Hiroshi Tamagawa, Ayako Tamagawa, Yosuke Atsumi, Shinnosuke Kawahara, Yukio Maezawa, Kazuki Kano, Masaaki Murakawa, Keisuke Kazama, Masakatsu Numata, Takashi Oshima, Munetaka Masuda, and Yasushi Rino made substantial contributions to acquisition of data, or analysis and interpretation of data. Norio Yukawa, Toru Aoyama, Hiroshi Tamagawa, Ayako Tamagawa, Yosuke Atsumi, and Shinnosuke Kawahara have been involved in drafting the manuscript or revising it critically for important intellectual content. Norio Yukawa, Toru Aoyama, Hiroshi Tamagawa, Ayako Tamagawa, Yosuke Atsumi, and Shinnosuke Kawahara have given final approval of the version to be published. Each author should have participated sufficiently in the work to take public responsibility for appropriate portions of the content; and agreed to be accountable for all aspects of the work in ensuring that questions related to the accuracy or integrity of any part of the work are appropriately investigated and resolved. All Authors read and approved the final manuscript.

\section{Acknowledgements}

This work was supported, in part, by the nongovernmental organization Yokohama Surgical Research Group, Dr. Masumi Kamachi (Tokyo Shinagawa Hospital), Dr. Ryuji Tominaga (Fukuoka Wajiro Hospital), Dr. Nobuko Yoshiki (Yoshiki Dermatology Clinic Ginza). The authors express their sincere gratitude to Ms. Akiko Yoshida, Ms. Yuka Maruyama, Ms. Minako Igarashi and Ms. Mariko Yamauchi for their excellent data management in this study.

\section{References}

1 Bray F, Ferlay J, Soerjomataram I, Siegel RL, Torre LA and Jemal A: Global cancer statistics 2018: GLOBOCAN estimates of incidence and mortality worldwide for 36 cancers in 185 countries. CA Cancer J Clin 68: 394-424, 2018. PMID: 30207593. DOI: $10.3322 /$ caac.21492 
2 Lordick F, Mariette C, Haustermans K, Obermannová R and Arnold D; ESMO guidelines Committee. Oesophageal cancer: ESMO Clinical Practice Guidelines for diagnosis, treatment and follow-up. Ann Oncol 27: v50-v57, 2016. PMID: 27664261.

3 NCCN: NCCN Clinical Practice Guidelines in Oncology. Available at: https://www.nccn.org/professionals/physician_gls/ default.aspx

4 Muro K, Lordick F, Tsushima T, Pentheroudakis G, Baba E, Lu Z, Cho BC, Nor IM, Ng M, Chen LT, Kato K, Li J, Ryu MH, Zamaniah WIW, Yong WP, Yeh KH, Nakajima TE, Shitara K, Kawakami H, Narita Y, Yoshino T, Van Cutsem E, Martinelli E, Smyth EC, Arnold D, Minami H, Tabernero J and Douillard JY: Pan-Asian adapted ESMO Clinical Practice Guidelines for the management of patients with metastatic oesophageal cancer: a JSMO-ESMO initiative endorsed by CSCO, KSMO, MOS, SSO and TOS. Ann Oncol 30: 34-43, 2019. PMID: 30475943. DOI: 10.1093/annonc/mdy498

5 Yuequan J, Shifeng C and Bing Z: Prognostic factors and family history for survival of esophageal squamous cell carcinoma patients after surgery. Ann Thorac Surg 90: 908-913, 2010. PMID: 20732516. DOI: 10.1016/j.athoracsur.2010.05.060

6 Kato H and Nakajima M: Treatments for esophageal cancer: a review. Gen Thorac Cardiovasc Surg 61: 330-335, 2013. PMID: 23568356. DOI: 10.1007/s11748-013-0246-0

7 Sobin LH, Gospodarowicz MK and Wittekind Ch: TNM classification of malignant tumours. $7^{\text {th }}$ edition. Chichester, West Sussex, UK; Hoboken, NJ: Wiley-Blackwell, 2010.

8 Brierley J, Gospodarowicz MK, Wittekind Ch. TNM classification of malignant tumours. $8^{\text {th }}$ edition. Chichester, West Sussex, UK; Hoboken, NJ: John Wiley \& Sons, Inc., 2017.

9 Aoyama T, Yamamoto N, Kamiya M, Murakawa M, Tamagawa H, Sawazaki S, Numata M, Shiozawa M, Kobayashi S, Ueno M, Morimoto M, Yukawa N, Oshima T, Yoshikawa T, Rino Y, Masuda $M$ and Morinaga $S$ : The lymph node ratio is an independent prognostic factor in pancreatic cancer patients who receive curative resection followed by adjuvant chemotherapy. Anticancer Res 38: 4877-4882, 2018. PMID: 30061263. DOI: 10.21873/anticanres.12801

10 Kim Y, Squires MH, Poultsides GA, Fields RC, Weber SM, Votanopoulos KI, Kooby DA, Worhunsky DJ, Jin LX, Hawkins WG, Acher AW, Cho CS, Saunders N, Levine EA, Schmidt CR, Maithel SK and Pawlik TM: Impact of lymph node ratio in selecting patients with resected gastric cancer for adjuvant therapy. Surgery 162: 285-294, 2017. PMID: 28578142. DOI: 10.1016/j.surg.2017.03.023

11 Kunisaki C, Shimada H, Nomura M, Matsuda G, Otsuka Y, Ono $\mathrm{H}$, Akiyama $\mathrm{H}$. Clinical impact of metastatic lymph node ratio in advanced gastric cancer. Anticancer Res 25: 1369-1375, 2005. PMID: 15865093.

12 Yamamoto Y, Ikoma H, Morimura R, Konishi H, Murayama Y, Komatsu S, Shiozaki A, Kuriu Y, Kubota T, Nakanishi M, Ichikawa D, Fujiwara H, Okamoto K, Sakakura C, Ochiai T and Otsuji E: The clinical impact of the lymph node ratio as a prognostic factor after resection of pancreatic cancer. Anticancer Res 34: 2389-2394, 2014. PMID: 24778048.
13 Kelty CJ, Kennedy CW and Falk GL: Ratio of metastatic lymph nodes to total number of nodes resected is prognostic for survival in esophageal carcinoma. J Thorac Oncol 5: 1467-1471, 2010. PMID: 20812404.

14 Xia W, Liu S, Mao Q, Chen B, Ma W, Dong G, Xu L and Jiang F: Effect of lymph node examined count on accurate staging and survival of resected esophageal cancer. Thorac Cancer 10: 11491157, 2019. PMID: 30957414. DOI: 10.1111/1759-7714.13056

15 Zhao Y, Zhong S, Li Z, Zhu X, Wu F and Li Y: Pathologic lymph node ratio is a predictor of esophageal carcinoma patient survival: a literature-based pooled analysis. Oncotarget 8: 6223162239, 2017. PMID: 28977940. DOI: 10.18632/oncotarget. 19258

16 Mariette C, Piessen G, Briez N and Triboulet JP: The number of metastatic lymph nodes and the ratio between metastatic and examined lymph nodes are independent prognostic factors in esophageal cancer regardless of neoadjuvant chemoradiation or lymphadenectomy extent. Ann Surg 247: 365-371, 2008. PMID: 18216546. DOI: 10.1097/SLA.0b013e31815aaadf

17 Chen SB, Weng HR, Wang G, Zou XF, Liu DT, Chen YP and Zhang H: Lymph node ratio-based staging system for esophageal squamous cell carcinoma. World J Gastroenterol 21: 7514-7521, 2015. PMID: 26139998. DOI: 10.3748/wjg.v21.i24.7514

18 Bhamidipati CM, Stukenborg GJ, Thomas CJ, Lau CL, Kozower $\mathrm{BD}$ and Jones DR: Pathologic lymph node ratio is a predictor of survival in esophageal cancer. Ann Thorac Surg 94: 1643-1651, 2012. PMID: 22621876. DOI: 10.1016/j.athoracsur.2012.03.078

19 Wilson M, Rosato EL, Chojnacki KA, Chervoneva I, Kairys JC, Cohn HE, Rosato FE Sr and Berger AC: Prognostic significance of lymph node metastases and ratio in esophageal cancer. J Surg Res 146: 11-15, 2008. PMID: 18028955.

20 Hou X, Wei JC, Xu Y, Luo RZ, Fu JH, Zhang LJ, Lin P and Yang HX: The positive lymph node ratio predicts long-term survival in patients with operable thoracic esophageal squamous cell carcinoma in China. Ann Surg Oncol 20: 1653-1659, 2013. PMID: 23247981. DOI: 10.1245/s10434-012-2794-4

21 Ooki A, Akagi K, Yatsuoka T, Asayama M, Hara H, Nishimura Y, Katoh H, Yamashita K, Watanabe M and Yamaguchi K: Lymph node ratio as a risk factor for recurrence after adjuvant chemotherapy in stage III colorectal cancer. J Gastrointest Surg 21: 867-878, 2017. PMID: 28251467. DOI: 10.1007/s11605$017-3382-5$

22 Ryan ÉJ, O'Sullivan DP, Kelly ME, Syed AZ, Neary PC, O'Connell PR, Kavanagh DO, Winter DC and O'Riordan JM: Meta-analysis of the effect of extending the interval after longcourse chemoradiotherapy before surgery in locally advanced rectal cancer. Br J Surg 106: 1298-1310, 2019. PMID: 31216064. DOI: 10.1002/bjs. 11220
Received March 31, 2020

Revised April 13, 2020

Accepted April 14, 2020 